\title{
Impact of Wheat-Barley Blending on Rheological, Textural and Sensory Attributes of Leavened Bread \\ Fiza Nazir ${ }^{1}$ and Nayik GA ${ }^{2 *}$
}

${ }^{1}$ Division of Post-Harvest Technology, SKUAST-Kashmir, India

${ }^{2}$ Department of Food Engineering and Technology, SLIET, Punjab, India

\begin{abstract}
The aim of the study was to develop a healthy alternative to wheat-leavened bread by using wheat-barley blended flour. The leavened breads were prepared by blending wheat and barley flour at different levels and varying the MSG concentration. A significant increase was observed in the extensibility of the dough with increase with increasing MSG concentration before fermentation while after fermentation it showed a significant decreasing effect. The highest value of color, taste and appearance was observed for $T_{2} M_{1}$. Results for the flavor of the breads revealed that the highest flavor score was observed for $\mathrm{T}_{2} \mathrm{M}_{2}$. The results showed that the overall acceptability score decreased with increasing barley flour and MSG level.
\end{abstract}

Keywords: Wheat flour; Barley flour; Leavened bread; MSG; Sensory analysis

\section{Introduction}

Barley (Hordeum vulgare L.) is an ancient and important cereal grain crop ranking fifth among all crops in dry matter production in the world. It is one of the most widely cultivated cereal crops that can provide valuable nutrients required by humans and domestic animals. The high adaptability of barley to various climates and growing conditions has led to its increased worldwide production. Barley is arguably the most widely adapted cereal grain species with production at higher latitudes and altitudes and farther in deserts than any other cereal crop. It is in extreme climates that barley remains a principal food source today, e.g. Himalayan nations, Ethiopia, and Morocco [1]. Whole barley grain consists of about $65 \%$ to $68 \%$ starch, $10 \%$ to $17 \%$ protein, $4 \%$ to $9 \% \beta$-glucan, $2 \%$ to $3 \%$ free lipids and $1.5 \%$ to $2.5 \%$ minerals [2-4]. Human consumption of barley and barley-containing food products has been insignificant as compared to other cereal grains, the development of new processes and food products has been neglected and there has been little effort to define quality requirements for food uses. The significance of $\beta$-glucan and tocols for human nutrition is well known, but little is known about the functional properties of $\beta$-glucan for making food products. Some of the traits preferred for specific food applications are known through investigations on incorporating barley into wheat-based food products. Barley flour, prepared from pearled grain through hammer milling or roller milling, has been incorporated into wheat based products, including bread, cakes, cookies, noodles and extruded snack foods [5]. Wheat bread with barley flour added at $15 \%$ to $20 \%$ was acceptable in overall flavour, appearance and texture, but an increased proportion of barley flour caused a decrease in loaf volume, dull brown colour and hard crumb texture $[6,7]$

Numbers of technologies have been developed for the development of different kinds of bread like to design and optimize processing, storage, and transport conditions and methodologies. Many cereals and their products required for bread making are efficient in one way but at the same time are lacking in other properties as well. The demand for the specialty breads and the role of wheat bran, barley and commercial celluloses and other cereals and their products in bread making is increasing day by day. In order to overcome these demands, various methods like blending of different cereals are used for the development of breads with specialized properties. With this background, the present work for the development of leavened bread by using wheatbarley blended flour was undertaken to study the rheological attributes of wheat-barley blended dough and to prepare breads from composite flours and evaluate the suitable level of barley flour supplementation.

\section{Materials and Methods}

The work was carried out in the department of food technology, Islamic University of Science and Technology Awantipora during the year 2010-2011. The wild barley was purchased from Ladakh and then milled in a mixer to obtain whole flour. The flour was stored in plastic air tight containers at refrigerated temperatures until used. Refined wheat flour, shortening, compressed yeast etc were purchased from local market of Srinagar. Composite flours were prepared as mentioned in Table 1. The formulations of the barley enriched breads were according to the Table 2. Breads were prepared from blended flour of wheat and barley according to the procedure shown in Figure 1. MSG was used at $0 \%, 0.3 \%$ and $0.5 \%$ level. The ingredients were weighed

\begin{tabular}{|c|c|c|c|c|}
\hline \multicolumn{2}{|c|}{ Treatment } & Concentration of MSG & Wheat flour (\%) & Barley flour (\%) \\
\hline \multirow{3}{*}{$\mathrm{T}_{1}$} & $\mathrm{~T}_{1} \mathrm{M}_{1}$ & $0.0 \%$ & $100 \%$ & $0 \%$ \\
\hline & $\mathrm{T}_{1} \mathrm{M}_{2}$ & $0.3 \%$ & $100 \%$ & $0 \%$ \\
\hline & $\mathrm{T}_{1} \mathrm{M}_{3}$ & $0.5 \%$ & $100 \%$ & $0 \%$ \\
\hline \multirow{3}{*}{$\mathrm{T}_{2}$} & $\mathrm{~T}_{2} \mathrm{M}_{1}$ & $0.0 \%$ & $90 \%$ & $10 \%$ \\
\hline & $\mathrm{T}_{2} \mathrm{M}_{2}$ & $0.3 \%$ & $90 \%$ & $10 \%$ \\
\hline & $\mathrm{T}_{2} \mathrm{M}_{3}$ & $0.5 \%$ & $90 \%$ & $10 \%$ \\
\hline \multirow{3}{*}{$\mathrm{T}_{3}$} & $\mathrm{~T}_{3} \mathrm{M}_{1}$ & $0.0 \%$ & $80 \%$ & $20 \%$ \\
\hline & $\mathrm{T}_{3} \mathrm{M}_{2}$ & $0.3 \%$ & $80 \%$ & $20 \%$ \\
\hline & $\mathrm{T}_{3} \mathrm{M}_{3}$ & $0.5 \%$ & $80 \%$ & $20 \%$ \\
\hline \multirow{3}{*}{$\mathrm{T}_{4}$} & $\mathrm{~T}_{4} \mathrm{M}_{1}$ & $0.0 \%$ & $70 \%$ & $30 \%$ \\
\hline & $\mathrm{T}_{4} \mathrm{M}_{2}$ & $0.3 \%$ & $70 \%$ & $30 \%$ \\
\hline & $\mathrm{T}_{4} \mathrm{M}_{3}$ & $0.5 \%$ & $70 \%$ & $30 \%$ \\
\hline
\end{tabular}

Table 1: Wheat-barley composite flours used for bread formulations.

*Corresponding author: Nayik GA, Department of Food Engineering and Technology, SLIET, Punjab-148106, India, Tel: +91-9697470552, Fax: 01672-280057; E-mail: gulzarnaik@gmail.com

Received June 21, 2016; Accepted July 08, 2016; Published July 14, 2016

Citation: Nazir F, Nayik GA (2016) Impact of Wheat-Barley Blending on Rheological, Textural and Sensory Attributes of Leavened Bread. J Food Process Technol 7: 611. doi:10.4172/2157-7110.1000611

Copyright: $\odot 2016$ Nazir F, et al. This is an open-access article distributed under the terms of the Creative Commons Attribution License, which permits unrestricted use, distribution, and reproduction in any medium, provided the original author and source are credited. 


\begin{tabular}{|c|c|}
\hline Wheat flour/composite flour & $150 \mathrm{~g}$ \\
\hline Yeast & $3.0 \mathrm{~g}$ \\
\hline Sugar & $6.0 \mathrm{~g}$ \\
\hline Salt & $1.5 \mathrm{~g}$ \\
\hline Shortening & $3.0 \mathrm{~g}$ \\
\hline
\end{tabular}

Table 2: Wheat-barley composite bread formulations.

Raw material<smiles>C1CCC1</smiles>

Addition of water containing yeast<smiles>C1CCC1</smiles>

Kneading (20 min.)

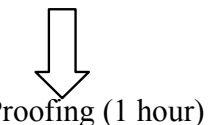<smiles>C1CCCC1</smiles>

Knock back<smiles>C1CCCC1</smiles>

Proofing (30 min.)<smiles>C1CC2CC1C2</smiles>

Filling in greased pans<smiles>C1CCCC1</smiles>

Proofing (35 min.)<smiles>C1CC2CC1C2</smiles>

Baking $\left(220^{\circ} \mathrm{C}\right.$ for $30-35 \mathrm{~min}$.)

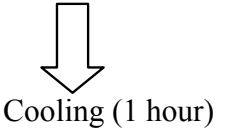<smiles>C1CC2CC1C2</smiles>

Slicing<smiles>C1CCCCC1</smiles>

Packing

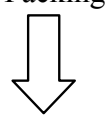

Storage

Figure 1: Flow chart for bread making. accurately and the yeast was activated in hot water. All the ingredients were mixed in a vessel and yeast was added while taking into account the amount of water. The dough was then placed in an incubator at $37^{\circ} \mathrm{C}$ for fermentation. Dough was taken out after 1 hour and then knocked back to remove the excess gases. The dough was again placed in incubator for fermentation and removed after 30 min, knocked back, rolled and moulded into pans and then allowed to ferment for another $35 \mathrm{~min}$. The pans were then placed in baking oven at $220^{\circ} \mathrm{C}$ for 30 $35 \mathrm{~min}$. The breads were taken out, cooled and then sliced. The breads were stored at room temperature.

\section{Rheological and textural analysis}

A Texture Analyzer was used to measure the extensibility and firmness (TA. HD. Plus, Stable Micro Systems, Godalming, Surrey, UK). For extensibility, the dough strip was placed onto the grooved region of the sample plate and the plate was inserted into the rig while holding down the spring loaded clamp lever. The handle was released slowly. The analysis was done to a distance of $75 \mathrm{~mm}$, at a pre-test speed of $2.0 \mathrm{~mm} / \mathrm{s}$, test speed of $3.3 \mathrm{~mm} / \mathrm{s}$, post-test speed of $10.0 \mathrm{~mm} / \mathrm{s}$ using a $5 \mathrm{Kg}$ load cell. For firmness, the sample was removed from its place of storage and was placed centrally over the supports just prior to testing. The texture profile analysis was done to a distance of $30 \mathrm{~mm}$ at pre-test speed of $1.0 \mathrm{~mm} / \mathrm{s}$, test speed of $1.7 \mathrm{~mm} / \mathrm{s}$ and a post- test speed of 10.0 $\mathrm{mm} / \mathrm{s}$ using a $5 \mathrm{Kg}$ load cell.

\section{Determination of organoleptic characteristics}

A panel of 10 judges evaluated the organoleptic characteristics of prepared breads. They assessed crust colour, appearance, flavour, texture, taste and overall acceptability, using a 9-point hedonic rating scale (9-Like extremely, 8 -Like very much, 7 -Like moderately, 6-Like slightly, 5-Neither like nor dislike, 4-Dislike slightly, 3-Dislike moderately, 2-Dislike very much, 1-dislike extremely). Tap water was provided to the panelists to rinse between evaluations.

\section{Statistical analysis}

The data was statistically analysed on a computer using design factorial in Completely Randomized Design (CRD) as suggested by Snedecor and Cochran [8].

\section{Results and Discussion}

Table 3 indicated that the mean values for extensibility statistically showed a significant increasing trend from 24.76 to 27.98 with addition of MSG. Further the highest mean extensibility was observed in $\mathrm{T}_{1}$ (33.51) and lowest mean extensibility was observed in $\mathrm{T}_{4}$ (18.46). These results are in accordance with the findings of Sternberg et al. [9] who observed increase in extensibility of dough due to the reducing action of MSG. MSG unexpectedly caused weakening of gluten structure for a relatively short period (before fermentation). The extensibility is primarily due to elasticity of glutenin proteins present in wheat, which may dilute with the addition of non-wheat flour resulting in decreased extensibility [10]. The mean values for extensibility showed a significant decreasing trend from 22.39 to 19.18 with addition of MSG (Table 4). The highest mean extensibility was observed in $\mathrm{T}_{1}$ treatment (28.19) and lowest mean extensibility was observed in $\mathrm{T}_{4}$ treatment (14.42). Similar results were found by Sternberg et al. [9] who reported that MSG caused strengthening of gluten network after fermentation due to the oxidative action. The decrease in extensibility with addition of barley flour is due to glutenin dilution.

Table 5 indicated that the mean values for firmness elucidated statistically showed a significant increasing trend from 26.60 to 44.73 
Citation: Nazir F, Nayik GA (2016) Impact of Wheat-Barley Blending on Rheological, Textural and Sensory Attributes of Leavened Bread. J Food Process Technol 7: 611. doi:10.4172/2157-7110.1000611

Page 3 of 4

\begin{tabular}{|c|c|c|c|c|}
\hline \multirow{2}{*}{ Treatment } & \multicolumn{3}{|c|}{ Extensibility } & \multirow{2}{*}{ Treatment mean } \\
\hline & $M_{1}$ & $M_{2}$ & $\mathbf{M}_{3}$ & \\
\hline $\mathrm{T}_{1}$ & 32.10 & 33.01 & 35.42 & 33.51 \\
\hline $\mathrm{T}_{2}$ & 26.93 & 28.18 & 30.40 & 28.50 \\
\hline $\mathrm{T}_{3}$ & 22.82 & 24.07 & 26.00 & 24.30 \\
\hline $\mathrm{T}_{4}$ & 17.17 & 18.10 & 20.12 & 18.46 \\
\hline MSG mean & 24.76 & 25.88 & 27.98 & - \\
\hline
\end{tabular}

CD at 5\%; Treatment mean $(T)=0.158 ; M S G$ mean $(M)=0.0132 ; \mathrm{T} \times \mathrm{M}=0.385 ; \mathrm{T}_{1}=$ Control bread $(100 \%$ W.F $)$ W.F = Wheat flour B.F = Barley flour; $\mathrm{T}_{2}=10 \%$ B.F:

$90 \%$ W.F; $T_{3}=20 \%$ B.F: $80 \%$ W.F; $T_{4}=30 \%$ B.F: $70 \%$ W.F; $M_{1}=0 \%$ MSG; $M_{2}=0.3 \%$ MSG; $M_{3}=0.5 \%$ MSG

Table 3: Extensibility $(\mathrm{mm})$ of wheat-barley dough at different concentrations before fermentation.

\begin{tabular}{|c|c|c|c|}
\hline \multirow{2}{*}{ Treatment } & \multicolumn{2}{|c|}{ Extensibility } & $\mathbf{M}_{3}$ \\
\cline { 2 - 4 } & $\mathbf{M}_{1}$ & 28.34 & 26.10 \\
\hline $\mathrm{T}_{1}$ & 30.12 & 23.15 & 21.32 \\
\hline $\mathrm{T}_{2}$ & 25.10 & 17.42 & 16.10 \\
\hline $\mathrm{T}_{3}$ & 19.40 & 15.12 & 19 \\
\hline $\mathrm{T}_{4}$ & 14.97 & 21.01 & 13.17 \\
\hline MSG mean & 22.39 & 14.42 & 19 \\
\hline
\end{tabular}

CD at 5\%; Treatment mean $(T)=0.15 ; M S G$ mean $(M)=0.048 ; T \times M=0.152 T_{1}=$ Control bread $(100 \%$ W.F $) ; W . F=W h e a t$ flour; B.F = Barley flour; $T_{2}=10 \%$ B.F: $90 \%$ W.F; $\mathrm{T}_{3}=20 \%$ B.F: $80 \%$ W.F; $\mathrm{T}_{4}=30 \%$ B.F: $70 \%$ W.F; $\mathrm{M}_{1}=0 \% \mathrm{MSG} \mathrm{M}_{2}=0.3 \% \mathrm{MSG} ; \mathrm{M}_{3}=0.5 \% \mathrm{MSG}$

Table 4: Extensibility $(\mathrm{mm})$ of wheat-barley dough at different concentrations after fermentation.

\begin{tabular}{|c|c|c|c|}
\hline \multirow{2}{*}{ Treatments } & \multicolumn{3}{|c|}{ Firmness } \\
\cline { 2 - 4 } & Day 1 & Day 2 & Day 3 \\
\hline $\mathrm{T}_{1} \mathrm{M}_{1}$ & 7.68 & 18.11 & 28.38 \\
\hline $\mathrm{T}_{1} \mathrm{M}_{2}$ & 11.00 & 23.92 & 36.83 \\
\hline $\mathrm{T}_{1} \mathrm{M}_{3}$ & 17.10 & 27.55 & 42.17 \\
\hline $\mathrm{T}_{2} \mathrm{M}_{1}$ & 10.04 & 15.20 & 27.52 \\
\hline $\mathrm{T}_{2} \mathrm{M}_{2}$ & 29.54 & 36.18 & 43.50 \\
\hline $\mathrm{T}_{2} \mathrm{M}_{3}$ & 33.10 & 41.73 & 47.02 \\
\hline $\mathrm{T}_{3} \mathrm{M}_{1}$ & 13.52 & 33.78 & 42.52 \\
\hline $\mathrm{T}_{3} \mathrm{M}_{2}$ & 30.28 & 43.55 & 46.60 \\
\hline $\mathrm{T}_{3} \mathrm{M}_{3}$ & 38.69 & 48.27 & 55.31 \\
\hline $\mathrm{T}_{4} \mathrm{M}_{1}$ & 28.05 & 34.51 & 42.62 \\
\hline $\mathrm{T}_{4} \mathrm{M}_{2}$ & 43.62 & 48.19 & 53.28 \\
\hline $\mathrm{T}_{4} \mathrm{M}_{3}$ & 56.56 & 62.35 & 71.03 \\
\hline $5: \mathrm{R}$ & & & \\
\hline
\end{tabular}

Table 5: Raw data for change in firmness $(\mathrm{N})$ of bread at different time intervals and with addition of MSG.

\begin{tabular}{|c|c|c|c|c|}
\hline \multirow{2}{*}{ Treatment } & \multicolumn{3}{|c|}{ Firmness } & $\begin{array}{c}\text { Treatment } \\
\text { mean }\end{array}$ \\
\cline { 2 - 4 } & Day1 & Day2 & Day3 & 23.63 \\
\hline $\mathrm{T}_{1}$ & 11.93 & 23.19 & 35.78 & 31.54 \\
\hline $\mathrm{T}_{2}$ & 24.23 & 31.04 & 39.36 & 39.16 \\
\hline $\mathrm{T}_{3}$ & 27.49 & 41.84 & 48.14 & 48.91 \\
\hline $\mathrm{T}_{4}$ & 42.74 & 48.35 & 55.64 & - \\
\hline Storage mean & 26.60 & 36.10 & 44.73 & -38 \\
\hline
\end{tabular}

$\mathrm{CD}$ at $5 \%$; Treatment mean $(\mathrm{T})=3.50$; Storage mean $(\mathrm{S})=2.93 ; \mathrm{T} \times \mathrm{S}=7.38$

Table 6: Change in firmness $(\mathrm{N})$ of bread during storage (Temperature $13^{\circ} \mathrm{C}$ to $18^{\circ} \mathrm{C}$ and relative humidity $64 \%$ to $63 \%$ ).

during three days of storage period. Further, the highest mean firmness was observed in $\mathrm{T}_{4}$ treatment (48.91) and lowest mean firmness was observed in $\mathrm{T}_{1}$ treatment (23.63). The results are in accordance with the findings of Goesaert et al. [11] who reported increase in firmness of bread during storage due to the transformation of gelatinised starch (amylopectin) network into an extensive, partially crystalline, permanent amylopectin network, with amylopectin crystallites acting as junction zones. The increase in firmness with addition of barley flour is due to gluten dilution. These results are in alignment with the findings of Gill et al. [12] who further reported that $\beta$-glucan in barley flour, when added to wheat flour during bread making, could tightly bind to appreciable amounts of water in the dough, suppressing the availability of water for the development of the gluten network. An underdeveloped gluten network can lead to increased bread firmness.

Table 6 indicated that the mean values for firmness elucidated statistically showed a significant increasing trend from 25.15 to 45.07 during storage with the addition of MSG. Further, the highest mean firmness was observed in $\mathrm{T}_{4}$ treatment (48.91) and lowest mean firmness was observed in $\mathrm{T}_{1}$ treatment (23.63). These results are in accordance with the findings of Gill et al. [12] who observed increase in firmness of bread with addition of barley flour due to gluten dilution.

\section{Organoleptic characteristics}

Crust colour: The highest value of colour was observed for $\mathrm{T}_{2} \mathrm{M}_{1}$ (7.5) and the lowest value of colour was observed for $\mathrm{T}_{4} \mathrm{M}_{2}$ (5.4) (Table 7). As the level of barley was increased in blends, the crust colour of the breads changed from creamy white to dull brown. Similar results were reported by Gupta et al. [13] and Dingra et al. [6].

Appearance: The appearance score for the control breads decreased significantly upon increasing the blending level to 20 and 30\% with barley. Among the blended breads, the highest appearance score was observed for $\mathrm{T}_{2} \mathrm{M}_{1}$ (7.1), whereas the lowest score was observed for $\mathrm{T}_{4} \mathrm{M}_{3}(5.0)$ (Table 7). These results are in quite similar with the findings of Gupta et al. [13].

Flavor: Results for the flavor of the breads revealed that the highest flavor score was observed for $\mathrm{T}_{2} \mathrm{M}_{2}$ (7.3), whereas the lowest score was observed for $\mathrm{T}_{4} \mathrm{M}_{1}$ (5.5). The flavor of barley-blended breads might be affected by the fibrous flavour of barley flour (Table 7). A similar decline in acceptability of breads due to strong flavor was observed by noticed by Dingra et al. [13]

Crust texture: The crust texture was related to the external appearance of the breads, i.e., smoothness or roughness of the crust. Crust texture score also decreased with increase in the substitution of barley and MSG in wheat flour as compared with the control sample. Among the blended bread, the highest score was observed for $T_{2} M_{1}$ 
Citation: Nazir F, Nayik GA (2016) Impact of Wheat-Barley Blending on Rheological, Textural and Sensory Attributes of Leavened Bread. J Food Process Technol 7: 611. doi:10.4172/2157-7110.1000611

Page 4 of 4

\begin{tabular}{|c|c|c|c|c|c|c|}
\hline Treatments & Colour & Texture & Taste & Flavor & Appearance & Overall acceptability \\
\hline $\mathrm{T}_{1} \mathrm{M}_{1}$ & 7.0 & 7.1 & 7.0 & 7.2 & 6.8 & 7.0 \\
\hline $\mathrm{T}_{1} \mathrm{M}_{2}$ & 7.0 & 7.1 & 7.0 & 7.0 & 6.7 & 7.1 \\
\hline $\mathrm{T}_{1} \mathrm{M}_{3}$ & 7.0 & 7.0 & 7.0 & 7.1 & 6.7 & 7.1 \\
\hline $\mathrm{T}_{2} \mathrm{M}_{1}$ & 7.5 & 7.2 & 7.6 & 7.2 & 7.1 & 7.4 \\
\hline $\mathrm{T}_{2} \mathrm{M}_{2}$ & 7.4 & 7.1 & 7.4 & 7.3 & 7.0 & 7.3 \\
\hline $\mathrm{T}_{2} \mathrm{M}_{3}$ & 7.4 & 7.0 & 7.3 & 7.2 & 7.0 & 7.2 \\
\hline $\mathrm{T}_{3} \mathrm{M}_{1}$ & 6.5 & 6.4 & 6.0 & 6.0 & 6.2 & 6.3 \\
\hline $\mathrm{T}_{3} \mathrm{M}_{2}$ & 6.4 & 6.2 & 6.1 & 6.2 & 6.0 & 6.2 \\
\hline $\mathrm{T}_{3} \mathrm{M}_{3}$ & 6.3 & 6.1 & 6.2 & 6.3 & 6.1 & 6.2 \\
\hline $\mathrm{T}_{4} \mathrm{M}_{1}$ & 5.8 & 5.3 & 5.1 & 5.5 & 5.3 & 5.4 \\
\hline $\mathrm{T}_{4} \mathrm{M}_{2}$ & 5.4 & 5.2 & 5.0 & 5.7 & 5.1 & 5.3 \\
\hline $\mathrm{T}_{4} \mathrm{M}_{3}$ & 5.5 & 5.0 & 5.1 & 5.6 & 5.0 & 5.1 \\
\hline
\end{tabular}

Table 7: Effect of blending on sensory quality of breads.

(7.2), whereas the lowest score was observed for $\mathrm{T}_{4} \mathrm{M}_{3}$ (5.0) (Table 7). Carson et al. [14] observed similar deterioration in the texture of wheat bread on supplementation.

Taste: Taste evaluation suggested that control and various supplemented breads had most satisfactory taste scores up to the $10 \%$ level. Results indicated that the highest taste score was observed for $\mathrm{T}_{2} \mathrm{M}_{1}$ (7.6), whereas the lowest score was observed for $\mathrm{T}_{4} \mathrm{M}_{2}$ (5.0) (Table $7)$. The decrease in taste score was because of the different flavor of flour blends [13].

Overall acceptability: The results showed that the overall acceptability score of all the supplemented breads at the $10 \%$ level was at par with the control (Table 7). Breads made from wheat and barley flour up to the $10 \%$ level were found acceptable, but at more than $10 \%$ substitution, the overall acceptability score was significantly reduced as compared with the control. In overall profile, the flavor of the breads was malty and fibrous at the $30 \%$ level of substitution. Based on the above results, breads containing $10 \%$ barley flour were found to be most acceptable by the sensory panelists.

\section{Conclusion}

The studies revealed that before fermentation the extensibility of the dough showed significant increase with addition MSG and significant decrease with addition of barley flour. After fermentation the extensibility of the dough showed a significant decreasing trend with addition of barley flour and MSG. Firmness of bread showed a significant increasing trend with addition of barley, MSG and with storage. It was concluded from the present studies that breads made from $10 \%$ barley flour blend proved superior with respect to sensory characteristics and were better than other blended breads as far as firmness and extensibility was concerned. Further investigations are required to evaluate the compositional and the antioxidant properties of these breads.

\section{Acknowledgement}

The first author is thankful to Department of Food Technology, IUST Awantipora, Pulwama J\&K, India for providing necessary facilities for lab work.

\section{References}

1. Baik B, Ullrich C (2008) Barley for food: Characteristics, improvement and renewed interest. J Cereal Sci 48: 233-242

2. Czuchajowska Z, Klamczynski A, Paszczynska B, Baik BK (1998) Structure and functionality of barley starches. J Cereal Chem 75: 747-754.

3. Izydorczyk MS, Storsley J, Labossiere D, MacGregor AW, Rossnagel BG, et al. (2000) Variation in total and soluble $\beta$-glucan content in hulless barley: Effects of thermal, physical, and enzymatic treatments. J Agri Food Chem 48: 982-989.

4. Quinde Z, Ullrich SE, Baik BK (2004) Genotypic variation in colour and discolouration potential of barley-based food products. J Cereal Chem 81: 752758.

5. Newman RK, Newman CW (1991) Barley as a food grain. J Cereal Food World 36: $800-805$

6. Dhingra S, Jood S (2004) Effect of flour blending on functional, baking and organoleptic characteristics of bread. Int J Food Sci Technol 39: 213-222.

7. Malik H, Nayik GA, Dar BN (2015) Optimisation of process for development of nutritionally enriched multigrain bread. J Food Process Technol 7: 544.

8. Snedecor GW, Cochran WG (1967) Statistical methods. The Lowa State University Press, USA.

9. Sternberg G, George P (1976) Preparation of yeast leavened dough products. J Food Addit 44: 100-110

10. Khatkar BS (2004) Dynamic rheological properties and breadmaking qualities of wheat gluten: Effects of urea and dithiothreitol. J Sci Food Agri 85: 337-341.

11. Goesaert H, Slade L, Levine H, Delcour AJ (2009) Amylase and bread firmingan integrated view. J Cereal Sci 50: 345-352.

12. Gill S, Vasanthan T, Ooraikul B, Rossnagel B (2002) Wheat bread quality as influenced by the substitution of waxy and regular barley flours in their native and extruded forms. J Cereal Sci 36: 219-237.

13. Gupta M, Bawa AS, Semwal AD (2011) Effect of barley flour blending on functional, baking and organoleptic characteristics of high-fiber rusks. J Food Process Preserv 35: 46-63.

14. Carson L, Setser C, Sun XS (2000) Sensory characteristics Food Sci Techno 35: $465-471$. 